\title{
Comparing Clinical Tests of Visual Function in Cataract with the Patient's Perceived Visual Disability
}

\author{
DAVID B. ELLIOTT, MARK A. HURST, JOHN WEATHERILL \\ Bradford
}

\begin{abstract}
Summary
Conventional techniques for assessing the visual function of cataract patients include visual acuity (VA), contrast sensitivity (CS) and glare disability (GD). The extent to which these measurements provide accurate information about a patient's perceived visual disability is not known. In this study, binocular and monocular VA and CS and monocular GD measurements were made using commercially available techniques on 33 cataract patients. VA was measured using a Ferris-Bailey LogMAR chart and CS by the Pelli-Robson letter CS chart. Glare disability was measured using the Mentor Brightness Acuity Tester in conjunction with both the LogMAR and Pelli Robson charts. Each patient's perceived visual disability was quantified using a 20 point questionnaire about the effect of vision on everyday activities. There was little correlation between subjective visual disability and monocular or binocular VA measurements. Measurements of binocular CS, however, were highly correlated with the patient's perceived visual disability, particularly their subjective assessment of the effect of vision on their mobility-orientation. We suggest that binocular CS measurements using the Pelli-Robson chart provide useful additional information regarding the need for surgery in cataract patients.
\end{abstract}

Recording visual acuity (VA) with a Snellen chart is the customary means of quantifying visual loss in cataract. The ability of this test to indicate the level of visual disability experienced by a cataract patient may however be limited. Bernth-Petersen ${ }^{1}$ used a questionnaire in an attempt to quantify the perceived visual disability of cataract patients. Out of 123 patients he found 25 with relatively good VA but with a high visual disability score, and suggested that these patients should have been operated on at an earlier age. Because of the very favourable risk-to-benefit ratio of modern cataract surgery, treatment is increasingly requested by symptomatic patients with relatively good VA and their subjective visual complaints have become indications for surgery. ${ }^{2-4}$ Obviously the level of incapacity that leads to interference with a patient's lifestyle depends on various factors such as occupation and hobbies; but the question remains-are there other psychophysical measures of visual function which would be better predictors of visual disability in cataract patients than VA? It has been suggested in numerous reports that contrast sensitivity (CS) and glare disability (GD) measurements provide a more comprehensive evaluation of visual function in cataract patients than VA alone. ${ }^{2-10}$ These studies have shown that CS and GD are significantly affected in cataract and cannot be predicted from VA measurements. We know of no previous reports, however, which have attempted to compare these psychophysical evaluations of visual function in cataract with the patient's perceived visual disability. 
In the present study, simple commercially available techniques, which can be readily used in the clinical environment, were used to measure CS and GD. Contrast sensitivity was measured on the Pelli-Robson letter CS chart $^{11}$ and GD with the Mentor Brightness Acuity Tester (BAT). ${ }^{12}$ We attempted to quantify the patient's perceived visual disability using a 20-point questionnaire concerning how their vision affected their everyday activities. $^{13}$

\section{Subjects}

Thirty three patients (mean age 68.3 \pm 9.8 years) with cataract in at least one eye and a wide range of VAs were recruited for the study (binocular VA range $6 / 4$ to $6 / 36$ ). Patients were either soon to begin an anticataract drug trial at the Clinical Vision Research Unit or were about to undergo cataract surgery. All subjects had been screened for ocular pathology by direct and indirect ophthalmoscopy after dilation and applanation tonometry. Subjects with intraocular pressure greater than $21 \mathrm{mmHg}$ or with any retinal disease were excluded. Subjects were also excluded with poor general health, diabetes, a refractive error greater than $\pm 6.00 \mathrm{DS}$, and any history of amblyopia. Four monophakic subjects were included. To ensure that any loss in visual function was due entirely to lens opacity, quantitative assessment of neural function behind the cataract was made using both the Rodenstock retinometer $^{14}$ and a hyperacuity technique. ${ }^{15}$ Any patients with an abnormal result from either test were excluded. ${ }^{16}$

\section{Methods}

All measurements were taken using natural pupils. After a full refraction, monocular and binocular LogMAR VA were measured at $4 \mathrm{~m}$ at a mean luminance of $160 \mathrm{~cd} / \mathrm{m}^{2}$ using the Ferris-Bailey charts. ${ }^{17}$ Monocular and binocular CS were measured using the Pelli-Robson letter chart. ${ }^{11,18}$ This consists of sixteen triplets of letters, with each letter subtending $3^{\circ}$ at the patients eye from $1 \mathrm{~m}$. The letters in each triplet have the same contrast and the contrast in each successive triplet decreases by a factor of $0.15 \mathrm{log}$ units. Pelli et al. ${ }^{11} \mathrm{sug}$ gest that when used at $1 \mathrm{~m}$ the chart gives an indication of $\mathrm{CS}$ at a spatial frequency between 0.5 and $2 \mathrm{c} /$ degree. The measurement procedure has been described previously, ${ }^{11,18}$ and typically most measurements take about three minutes to complete.

Two methods of measuring GD using the BAT were used. The BAT is a hand-held instrument which consists of a hemisphere with an illuminated surface having a central $12 \mathrm{~mm}$ aperture. Logmar VA and letter CS were both remeasured with the patient looking through the BAT aperture with the bowl illuminated to $300 \mathrm{~cd} / \mathrm{m}^{2}$. GD is measured as the reduction in VA (GDva) and CS (GDcs). The BAT can only take monocular measurements, and GD was measured using the eye with the worse VA.

To avoid familiarisation with the letters on the charts, all three versions of the FerrisBailey logMAR VA chart and both sides of the Pelli-Robson chart were used in a random sequence.

\section{Questionnaire}

Perceived visual disability was assessed using a twenty point questionnaire developed by $\mathrm{Mr}$ Ken Lowe of the University of Bristol Ophthalmology Department. Three of the questions asked for qualitative answers such as; please list any hobbies you find difficult because of your eyesight. The responses to the remaining seventeen questions were quantified using $10 \mathrm{~cm}$ Rosser line rating scales. ${ }^{13}$ The left hand end of the $10 \mathrm{~cm}$ line represents normality and the right hand end extreme handicap. The patient is asked to mark the line at a point between the two extremes which best represents their level of disability. Three questions asked the patient to describe their sight using their right, left and both eyes by marking the Rosser line somewhere between limits of 'normal' and 'severely reduced'. Thirteen questions asked the patient to describe the effect of vision on everyday activities by marking the Rosser line between limits of 'no problem' and 'extreme difficulty'. The final question asked whether the patients ever felt in any danger because of their eyesight. It has been suggested that many people with low vision could travel, but choose not to because they feel it is too dangerous. ${ }^{19,20}$ Responses were recorded on 
the Rosser line between limits of 'no danger' and 'extreme danger'. The distance of each mark from the 'normal' left hand limit on the Rosser lines were later measured to the nearest $1 \mathrm{~mm}$ and a score between 0.0 and 10.0 was recorded for each question.

\section{Results}

Three of the seventeen quantifiable responses had maximum values less than 3.0 , indicating that none of the 33 patients had any visual difficulty with these tasks. These were not used in any analysis. Paraphrased versions of the remaining fourteen questions are shown in Table I, and are numbered for later reference.

Pearson product-moment correlation coefficients were performed between the calculated scores from each of the fourteen questions shown in Table $I$ and the clinical measurements of visual function. Table II displays the question scores which were correlated significantly with each psychophysical measurement. The question numbers can be found in Table $\mathrm{I}$.

Previous studies using a questionnaire to evaluate perceived visual disability have grouped a number of questions together which relate to similar categories of visual disability and calculated a mean score for each category. ${ }^{21,22}$ The two most important tasks, judging by complaints of people with low vision are mobility and near vision. ${ }^{19}$ We divided the fourteen questions into three categories of mobility, near vision and discrimination. The mobility factor was calculated as the mean score from the responses to

Table I Paraphrased versions of questions used in the statistical analyses

\begin{aligned} & \hline 1. Vision in right eye. \\ & 2. Vision in left eye \\ & 3. Vision using both eyes. \\ & 4. Walking outside \\ & 5. Crossing road. \\ & 6. Driving \\ & 7. Bright sunlight. \\ & 8. Recognising your friends. \\ & 9. Reading bus numbers \\ & 10. Watching TV. \\ & 11. Telling the time. \\ & 12. Reading normal print books. \\ & 13. Reading a newspaper. \\ & 14. Danger. \\ & \hline\end{aligned}

questions 4,5,6,7 and 14 (see Table I). The assessment of how much danger the patients felt they were under because of their poor vision was included in this category because many low vision patients often do not leave their homes because of a fear of unexpected hazards when travelling. ${ }^{19,20}$ The near vision factor was calculated from the mean score from the responses to questions 12 and 13, and the discrimination factor using questions $8,9,10$ and 11 . The significant $(\mathrm{p}<0.05)$ correlation coefficient values between each psychophysical measurement and the scores from each category of perceived visual disability are shown in Table III.

Correlation coefficients depend on the range of values in two samples, as well as the strength of the relationship between them. ${ }^{23}$ A wide range will tend to give a greater correlation than a narrow one. ${ }^{23,24}$ The range of psychometric measurement values used to calculate correlation coefficients are, therefore, shown in Table IV.

\section{Discussion}

The three questions which were excluded from statistical analysis because none of the patients had any significant difficulty with the task involved, were all connected with tasks or mobility indoors. Although cataract patients may experience difficulties in mobility outdoors, the results confirm that this is much less of a problem in the familiar surroundings of their own home. The greater variation in light levels outdoors may also be a factor. The question scores which showed the least correlation with any clinical measure of visual function were 1,2,3 and 11. Questions 1,2 and 3 ask the patient to describe their vision in the right eye, left eye and binocularly. The results suggest that patients are poor at providing a global description of their visual disability. This was particularly noticed for some patients with different degrees of monocular cataract. Patients would describe their vision in their 'best' eye as nearly 'normal' and that of their 'worst' eye at the other limit of 'severely reduced' despite there being little difference in the VA or CS between the two eyes. The binocular vision would invariably be scored around the midpoint of the Rosser Line. 
Table II The question numbers whose scores were significantly correlated to each psychophysical measurement of visual function

\begin{tabular}{|c|c|c|c|c|c|c|c|c|}
\hline \multirow{3}{*}{$\begin{array}{l}\text { Psychophysical } \\
\text { measurement }\end{array}$} & \multicolumn{8}{|c|}{$\begin{array}{l}\text { p-values of correlation coefficients between } \\
\text { psychophysical measurement and question score. }\end{array}$} \\
\hline & \multicolumn{3}{|c|}{$p<0.05$} & \multicolumn{2}{|l|}{$p<0.01$} & \multicolumn{3}{|c|}{$<0.001$} \\
\hline & 7 & 12 & & 13 & & & & \\
\hline Worst eye VA & 4 & 12 & & 13 & & 6 & & \\
\hline Best eye VA & 12 & & & 13 & & & & \\
\hline Binocular CS & 9 & 10 & & 4 & 12 & 5 & 13 & 14 \\
\hline Worst eye CS & 4 & & & 5 & & 6 & & \\
\hline Best eye CS & 5 & $9 \quad 10$ & 14 & & & 12 & 13 & \\
\hline GDva & 1 & & & & & 12 & 13 & \\
\hline GDcs & 4 & 8 & & & & & & \\
\hline
\end{tabular}

Measurement of VA is the customary measure of visual loss in patients with cataract. VA measurements were best correlated with patient's reported difficulty in reading newspapers and books. This is not surprising as both require the ability to resolve high contrast letters. None of the VA measurements correlated well, however, with other aspects of visual disability, such as travelling outside the home and seeing peoples faces. The decision of when to extract a cataract is often influenced by the VA of the 'best' eye. It is thought that if vision is good in one eye then the overall visual functioning must be adequate. ${ }^{25}$ Visual disability as determined from the responses to the questionnaire is better correlated with VA of the 'worst' eye than either of the other VA measurements. Although this may be due in part to the differences in the range of Logmar VA scores used to calculate the correlation coefficients (see Table IV), it does suggest that the 'worst' eye has an important effect on perceived visual disability. ${ }^{26-28}$
The Pelli-Robson chart is purported to indicate CS over a small range of low and intermediate spatial frequencies. ${ }^{11}$ Measurements of binocular CS using the Pelli-Robson chart were shown to correlate best with the patient's perceived visual disability, particularly their mobility outdoors. Similarly, Marron and Bailey ${ }^{29}$ found that orientationmobility performance of low vision patients was significantly correlated to their peak CS and visual field loss but not their VA. Low spatial frequency CS has also been shown to be more important than VA in viewing everyday 'real world' targets such as faces. ${ }^{30}$ Lennerstrand and Ahlstrom ${ }^{22}$ found that CS measurements using letters were a better predictor of perceived visual disability in patients with macular degeneration than VA scores or CS using grating targets.

Unfortunately, binocular GD measurements could not be taken with the BAT, and measurements were taken from the 'worst' eye only. The results of the correlations with perceived visual disability suggest that GDva

Table III The correlation coefficient values between each psychophysical measurement and calculated questionnaire scores of three categories of visual disability. (N.S. indicates that the correlation coefficient was not significant at the $95 \%$ level)

\begin{tabular}{lccc}
\hline $\begin{array}{l}\text { Psychophysical } \\
\text { measurement }\end{array}$ & Mobility & $\begin{array}{c}\text { Visual disability category } \\
\text { Near Vision }\end{array}$ & Descrimination \\
\hline Binocular VA & N.S. & $0.41^{*}$ & N.S. \\
Worst eye VA & $0.52^{* *}$ & $0.46^{* *}$ & $0.41^{* *}$ \\
Best eye VA & N.S. & $0.42^{*}$ & N.S. \\
Binocular CS & $-0.65^{* * *}$ & $-0.60^{* * *}$ & $-0.49^{* *}$ \\
Worst eye CS & $-0.50^{* *}$ & $-0.35^{*}$ & N.S. \\
Best eye CS & $-0.50^{* *}$ & $-0.67^{* * *}$ & $-0.43^{*}$ \\
Worst eye GDva & N.S. & $0.61^{* *}$ & $0.57^{* *}$ \\
Worst eye GDcs & N.S. & N.S. & $0.45^{*}$ \\
\hline
\end{tabular}

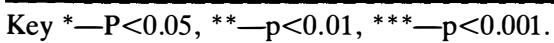


Table IV The total range and standard deviation of values obtained from 33 cataract patients for each psychophysical measurement

\begin{tabular}{lcc}
\hline $\begin{array}{l}\text { Psychophysical } \\
\text { measurement }\end{array}$ & $\begin{array}{c}\text { Total range } \\
\text { (log units) }\end{array}$ & $\begin{array}{c}\text { Standard deviation } \\
\text { (log units) }\end{array}$ \\
\hline Binocular VA & 0.94 & 0.22 \\
'Worst' eye VA & 1.04 & 0.32 \\
'Best' eye VA & 0.68 & 0.17 \\
Binocular CS & 1.05 & 0.25 \\
'Worst' eye CS & 1.65 & 0.45 \\
'Best' eye CS & 0.65 & 0.21 \\
GDva & 0.54 & 0.13 \\
GDcs & 0.60 & 0.21 \\
\hline
\end{tabular}

may provide additional information over VA (see Tables II and III). Of the CS measurements, CS for the 'worst' eye was the least predictive of perceived visual disability. GDcs was measured using the patient's 'worst' eye only and the range of log CS values used to calculate the correlation coefficients was small (see Table IV), which may explain the poor correlation of GDcs with perceived visual disability. Binocular GDcs measurements may provide more useful information than monocular. A number of GD tests are now commercially available which use a variety of targets and glare sources. ${ }^{3,4,31}$ Each is likely to affect cataractous eyes in different ways and differ in the real-life situations that they simulate. ${ }^{4}$

\section{Conclusion}

The study indicates that the Pelli-Robson chart and the Brightness acuity tester provide simple and quick clinical tests of CS and GD which supply additional information about the perceived visual disability of cataract patients. Binocular measurements of CS were the most highly correlated with the patients perceived visual disability, and were superior to the conventional measurement of VA. We suggest that such measurements would provide valuable information regarding the need for surgery in cataract patients.

We would like to thank Dr. David Whitaker and Dr Mark Bullimore for helpful discussion. Mark Hurst is receiving a research grant from Angelini Pharmaceuticals.

\footnotetext{
References

${ }^{1}$ Bernth-Petersen B: Visual functioning in cataract patients. Acta Ophthalmol 1981, 59: 198-205.

${ }^{2}$ Cinotti AA: Evaluations of indications for cataract surgery. Ophthalmic Surg 1979, 10: 25-31.
}

${ }^{3}$ Maltzmann BA, Horan C, Rengel A: Penlight test for glare disability in cataract patients. Ophthalmic Surg 1988, 19: 356-8.

${ }^{4}$ Koch DD: Glare and contrast sensitivity testing in cataract patients. J Cataract Refract Surg 1989, 15: 158-63.

${ }^{5}$ Harbin TS: Visual impairment by sunlight in posterior subcapsular cataracts. Ophthalmic Surg 1973, 4: 34-6.

${ }^{6}$ Hess R and Woo G: Vision through cataracts. Invest Ophthalmol Vis Sci 1978, 17: 428-35.

${ }^{7}$ Paulsson LE and Sjöstrand J: Contrast sensitivity in the presence of a glare light. Invest Ophthalmol Vis Sci 1980, 19: 401-6.

${ }^{8}$ Skalka HW: Arden grating test in evaluating 'early' posterior subcapsular cataracts. South Med J 1981, 74: 1368-70.

${ }^{9}$ Woo GC: Contrast sensitivity as a diagnostic tool in low vision. Am J Optom Physiol Opt 1985, 62: 648-51.

${ }^{10}$ Elliott DB, Gilchrist J, Whitaker D: Contrast sensitivity and glare sensitivity in three types of cataract morphology: Are these techniques necessary in a clinical evaluation of cataract? Ophthal Physiol Opt 1989, 9: 25-30.

${ }^{11}$ Pelli DG, Robson JG, Wilkins AJ: The design of a new letter chart for measuring contrast sensitivity. Clin Vis Sci 1988, 2: 187-99.

${ }^{12}$ Holladay JT, Prager TC, Truillo J, Ruiz RS: Brightness acuity test and outdoor visual acuity in cataract patients. J Cataract Refract Surg 1987, 13: 67-9.

${ }^{13}$ Guidex GM and Kind P: The QALI tool kit. Discussion paper No. 38, Centre for health economics. York University, 1988.

${ }^{14}$ Fuller DG and Hutton WL: Presurgical evaluation of eyes with opaque media. London. Grune and Stratton, 1982 .

${ }^{15}$ Whitaker D and Elliott DB: Towards establishing a clinical displacement threshold technique to evaluate visual function behind cataract. Clin Vis Sci 1988, 4: 61-9.

${ }^{16}$ Elliott DB and Hurst MA: Assessing the progress of cataract: A clinical evaluation of the opacity lensmeter 701. Optom Vis Sci 1989, 66: 257-63.

${ }^{17}$ Ferris FL, Kassof A, Bresnick GH, Bailey I: New visual acuity charts for clinical research. Am J Ophthalmol 1982, 94: 91-6.

${ }^{18}$ Elliott DB, Sanderson K, Conkey A: The reliability 
of the Pelli-Robson contrast sensitivity chart. Ophthal Physiol Opt 1990, 10: 21-4.

${ }^{19}$ Pelli DG: The visual requirements of mobility. In Woo GC (ed) Low Vision. New York. SpringerVerlag 1986; 134-146.

${ }^{20}$ Faye EE: Low vision management in selected eye diseases. In Woo GC (eds) Low Vision, New York. Springer-Verlag 1986; 96-107.

${ }^{21}$ Ross JE, Bron AJ, Clarke DD: Contrast sensitivity and visual disability in chronic simple glaucoma. Br J Ophthalmol 1984, 68: 821-7.

${ }^{22}$ Lennerstrand $G$ and Ahlstrom CO: Contrast sensitivity in macular degeneration and the relation to subjective visual impairment. Acta Ophthalmol 1989, 67: 225-33.

${ }^{23}$ Bland JM and Altman DG: Statistical methods for assessing agreement between two methods of clinical measurement. Lancet 1986, i: 307-11.

${ }^{24}$ Elliott DB and Sheridan M: The use of accurate visual acuity measurements in clinical anti-cataract formulation trials. Ophthal Physiol Opt 1988, 8: $397-401$.
${ }^{25}$ Bernth-Petersen B: A change in indications for cataract surgery? A 10-year comparative epidemiologic study. Acta Ophthalmol 1981, 59: 206-10.

${ }^{26}$ Gilchrist J and McIver C: Fechner's paradox in binocular contrast sensitivity. Vision Res 1985, 25: 609-13.

${ }^{27}$ Gilchrist J and Pardhan S: Binocular contrast detection: A new model predicting summation and inhibition. Invest Ophthalmol Vis Sci (suppl) 1988, 29: 411.

${ }^{28}$ Pardhan S and Gilchrist J: Binocular contrast sensitivity with monocular glare disability. Ophthal Physiol Opt 1990, 10: 37-39.

${ }^{29}$ Marron JA and Bailey IL: Visual factors and orientation-mobility performance. Am J Optom Physiol Opt 1982; 59: 413-26.

${ }^{30}$ Owsley C and Sloane M: Contrast sensitivity, visual acuity and perception of 'real world' targets. $\mathrm{Br} J$ Ophthalmol 1987, 71: 791-6.

${ }^{31}$ Neumann AC, McCarthy GR, Locke J, Cobb B: Glare disability devices for cataractous eyes: A consumers guide. J Cataract Refract Surg 1988, 14: $212-6$. 